\title{
Re-design punch and die of the laboratory pharmaceutical tablet press machine
}

\author{
Ramiz Saeed Matty Samarjy \\ University of Mosul / College of Engineering \\ Mech. Engineering . Department
}

\begin{abstract}
This research represents an attempt to solve a problem introduced by Ninevah drug factory to increase the out put of one of its laboratory machine located in research sector .

First of all, thinking was for selection a suitable material of punches and die compatible with the surrounding environments of different drug powders as they represents corrosive agents to the metal that in touch .Beside that this material primarly must be capable of being machined to manufacture the required design, Also it is capable to be heat treated after manufacturing .

Second,we should redesign the punch and die with the same surrounding spans limitation but with increasing the number of used punches and redistributing them in a suitable manner in its restricted die, and manufacturing punches with a different sizes $(7,9$, 7.9,10.3,12.53 $) \mathrm{mm}$ in diameter as the factory demand taking into account the concave and convex of pair of punches to create the mirror shape of tablet after pressing is completed . All that will be done must give the standardized weight, size and optimum compressibility according to the certificate of the quality control unit.
\end{abstract}

Keywords: punch, die, tablet, powder.

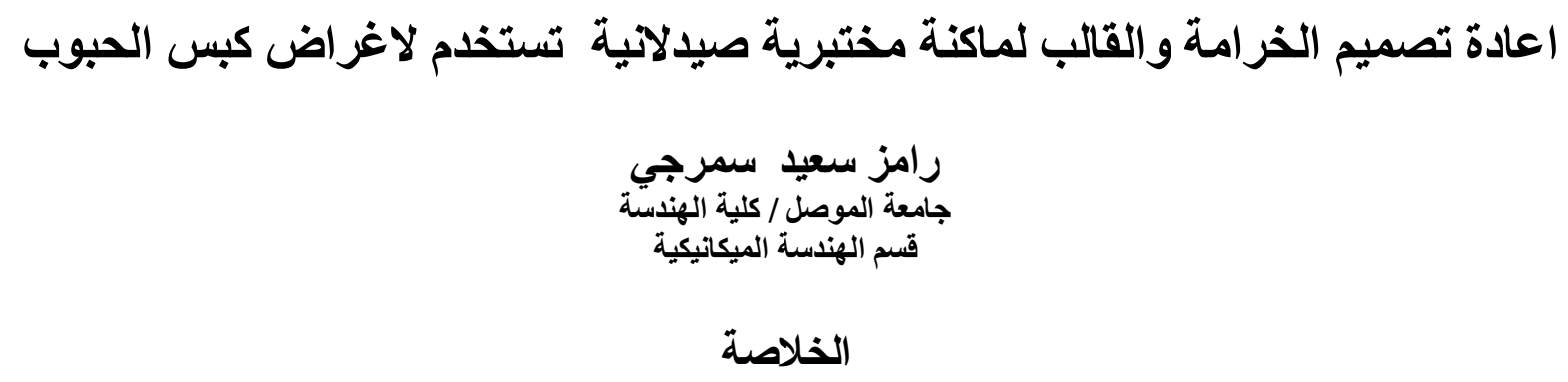

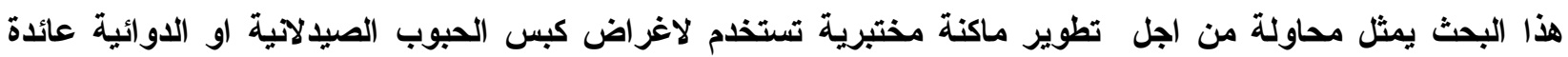

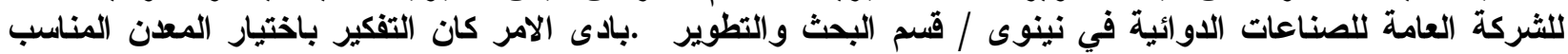

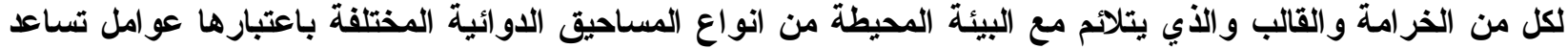

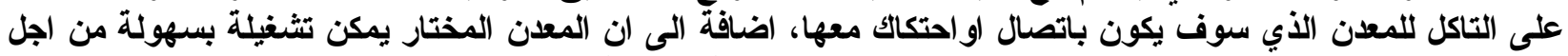

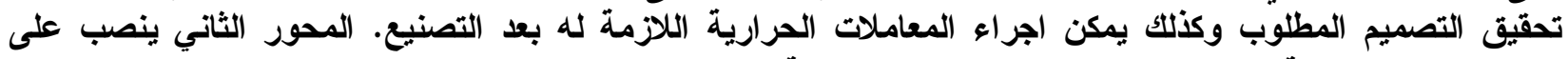

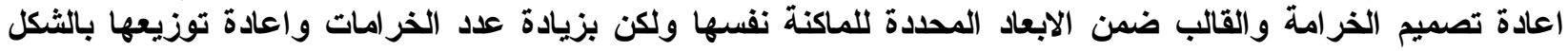

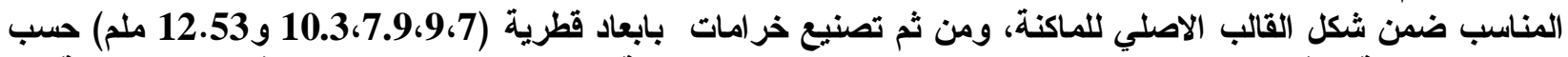

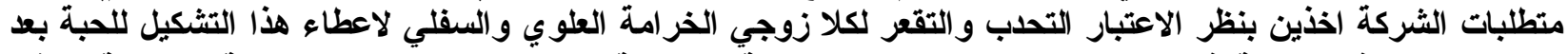

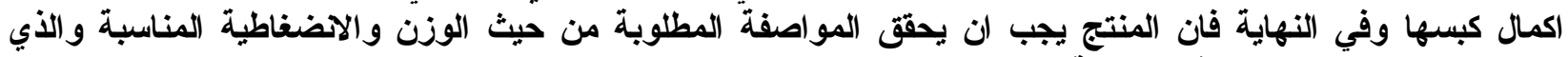

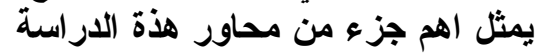
الكلمات الدالة ( خرامة ، قالب ، حبة ، مسحة ، مسحق) 


\section{Introduction}

Powder compaction is a process widely used in many industries. For instance, in the powder metallurgy and ceramic industries, powders are generally compacted into a green body before being sintered at high temperature to manufacture engineering components. In chemical engineering, detergent tablets are made of dry powder through a powder compaction process. In the pharmaceutical industry, billions of tablets are produced on a daily basis by compacting pharmaceutical powders. The use of compaction for pharmaceuticals is mainly due to various advantages of tablets over other dosage forms, such as chemical and physical stability, acceptable shelf life, accuracy of dosage and ease of controlling drug release . From the manufacturing point of view, tablets can be mass-produced with high production rates The processing of tabletting is similar to the process of other powder compacts and can generally be divided into. three distinct stages:

(1) die filling, where the blends of powder mixes are delivered into a feed shoe which runs over the die opening before depositing the powder into the die cavity under gravity

(2) compaction, where the powder is compressed inside a die by two punches;

(3) ejection, where the compact is ejected from the die. [1,2]; The powder behavior during the above three stages all determine the properties of final compacts. Therefore, understanding the mechanical behavior of powders during each stage is very important and has attracted significant attention over the past several decades. According to the movement of the upper punch, the compaction process can be divided into two phases: compression and decompression. During compression, as the upper punch moves towards the bottom punch, the powder bed experiences intensive densification and the powder particles move together to form aggregates with appreciable cohesive strength [3].As the distance between two punches continues to decrease, the compaction pressure and the packing density of the powder bed increase dramatically. Many previous studies have concentrated on the relation between relative density and increasing compaction pressure $[4,6]$. This relation is material-dependent and is regarded as a measure of compressibility of the materials. A number of models have been developed and modified to characterize the powder compressibility more accurately [3,7]. Although no direct evidence of densification mechanisms has yet been reported, it is often thought that particle rearrangement and collapse of granules are the dominant behaviors at low pressure. As the pressure increases, the elastic and plastic deformation of constituent particles becomes dominant. Further increases in compaction pressure may result in fragmentation of the primary particles, which then causes further densification of the powder bed. Decompression takes place once the upper punch starts to move away from the lower punch. During this stage, the compaction pressure drops quickly as the distance between the two punches increases, and some of the elastic strain induced during compression will recover. This is accompanied by an increase in the volume of the powder bed and a consequent decrease in the relative density. Controlling the elastic recovery rate is crucial in the processing of powder compacts because defects, are more likely to be induced by faster elastic recovery, or spring-back, during decompression. such as defects and fracture of powder compacts, sticking, picking, capping and lamination, can occur during tabletting by uniaxial die compaction. Although several simple theories have been used to explain the causes of failure [8], more detailed simulation and analysis of the tabletting process are imperative in order to quantitatively predict the occurrence of tablet failure and how it may manifest. Moreover, simulation of the tabletting process can also help to understand the influence of tooling properties, lubrication and compaction kinematics (e.g. compaction speed and compaction sequences), and provide the guidance for the optimisation of tooling design and the 
improvement of the powder formulation. the continuum model method was more suitable for engineering applications. Although a pharmaceutical powder is clearly discontinuous at the particle level, this becomes irrelevant at a larger scale of aggregation such as when it is compacted into a relatively dense compact in a die during tabletting. Therefore, the compaction behavior of pharmaceutical powders can be studied using the principles of continuum mechanics such as critical state models like Cam-Clay plasticity models and Cap plasticity models, which were originally developed for geological materials in soil mechanics, turned out to be well suited for modeling powder compaction, especially in powder metallurgy [9,10,11]. More recently, Drucker-Prager Cap plasticity models have been used for the analysis of compaction of pharmaceutical powders, because they can represent the densification and hardening of the powder, as well as the interparticle friction[12,13]. However, in these studies, the Young's modulus and Poisson's ratio were assumed to be constant, which was not suitable to describe the observed nonlinear unloading behavior of pharmaceutical powders and understand the elastic recovery of compacts during unloading and ejection. This is particularly important for tablet fracture, since the elastic recovery may initiate the cracks within compacts and produce catastrophic flaws, causing the compaction failures such as capping, lamination and chipping [14]. Moreover, the unsuitable material parameter identification for Drucker-Prager Cap models may result in an unrealistic simulation of the decompression phase of compaction, where the plastic strain almost vanished after decompression [15].

The objective of this study is to redesign the punch and die of pharmaceutical laboratory press tablet machine in research sector of Nineveh drug factory to increase the out put of this machine ( size $7 \mathrm{~mm}$ with one lower and upper punch only ) and manufacturing another punches and dies for producing another sizes of tablets which must be successfully compacted and cover especially the physical requirements of quality control sector.

\section{Characterising compaction behavior of pharmaceutical powders}

To characterise the compaction behavior of the powders, uniaxial die compaction equipment has been used to investigate the compaction behavior of pharmaceutical powders and to measure the radial die wall pressure and investigate the powder friction at the die wall during compaction, The axial upper/lower punch forces and displacements, and the radial die wall pressure are measured during compaction (see Fig. 1). The axial stress, $\sigma_{Z}^{U}$ was calculated from the upper punch force divided by the cross-section area of the compact; the axial strain, $\varepsilon_{Z}$ was calculated from the powder height change $(\Delta H)$ divided by its initial filling height $\left(H_{0}\right)$ in the die. Both the loading and unloading curves exhibit nonlinear behaviour. Moreover, the unloading curves at different compaction densities (or heights) are not parallel, i.e. the unloading properties are density-dependent. The axial to radial stress transmission during unloading (Fig. 2b), related to Poisson's ratio, also shows nonlinear behavior. Note that the density value shown in Fig. 2 is the compaction density calculated from the powder weight divided by the in-die powder volume

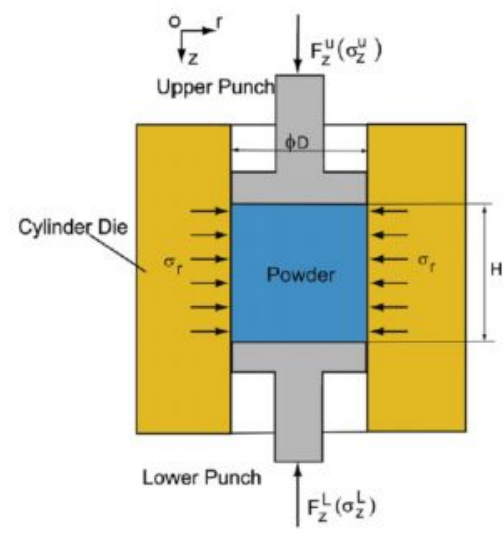

Figure (1) Diagram of instrumented Die 

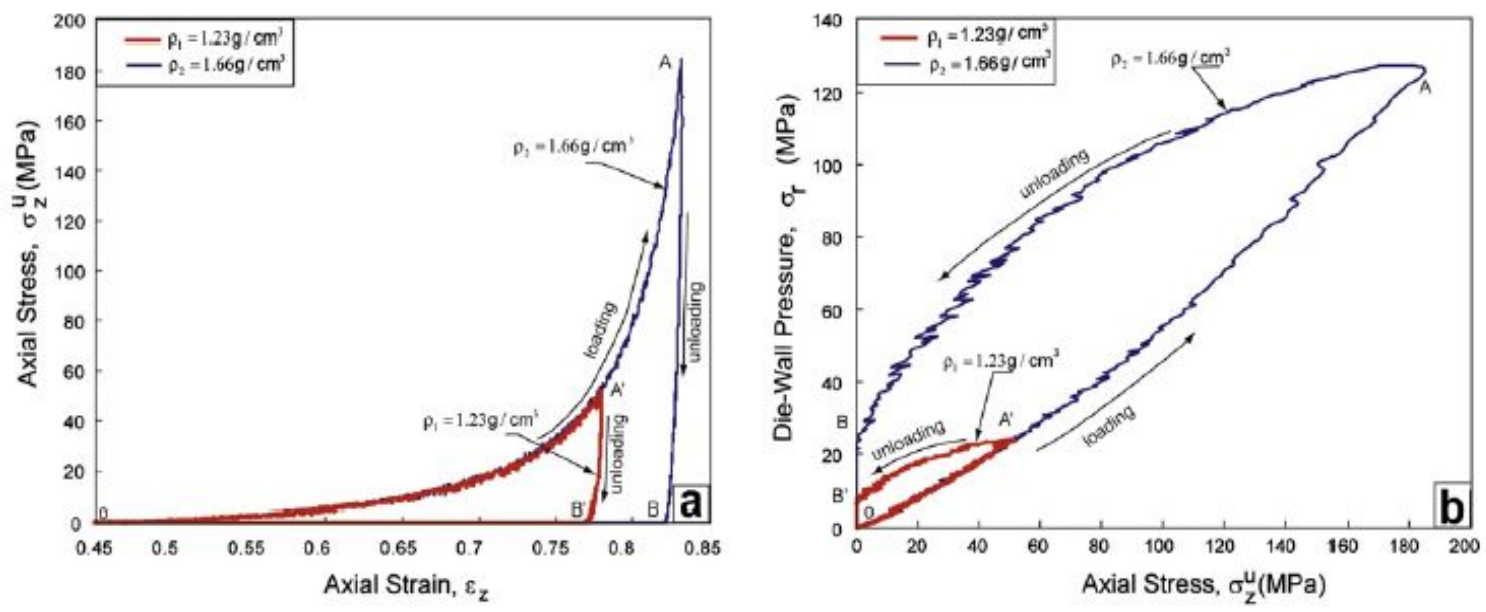

Figure (2) - (a)a typical axial Stress - Strain relation - (b) a typical stress transmission from axial stress to radial wall pressure [ 16 ].

The friction between the powder bed and the die wall plays an important role during the processing of powder compacts. The testing data are analysed based on Janssen-Walker theory [7,8]. In this theory, a cylindrical powder bed is considered (see Fig. 3). By assuming the vertical stresses are uniformly distributed on horizontal cross sections, force equilibrium for an arbitrary elemental slice $\mathrm{dz}$ at a distance $\mathrm{z}$ from the bottom of the powder bed gives[15]:

$\frac{\pi D^{2}}{4} d \sigma_{z}+\rho \frac{\pi D^{2} d z}{4} g=\tau_{z} \pi D d z$

Where $\sigma_{z}$ and $\boldsymbol{\tau}_{z}$ are the axial and shear stresses at a height of $\mathrm{z}$, respectively, D is the diameter of the cylindrical powder bed, $\rho$ and $\mathrm{g}$ are the density of the powder and gravity acceleration, respectively. Since the gravitational force is relatively small compared to the compression stresses, it can hence be neglected and the second item in the left-hand side of Eq. (1) can be omitted. The radial stress on the slice $d_{z}, \sigma_{z}$ can be related to the vertical stress, $\sigma_{z}$ by[15]

$\sigma_{r}=k \sigma_{z}$

where $\mathrm{k}$ is the stress transmission ratio. The shear stress due to friction acting on the slice $\mathrm{dz}$ can be given by Coulomb'slaw of friction [15] :

$\tau_{z}=\mu \sigma_{\mathrm{r}}$

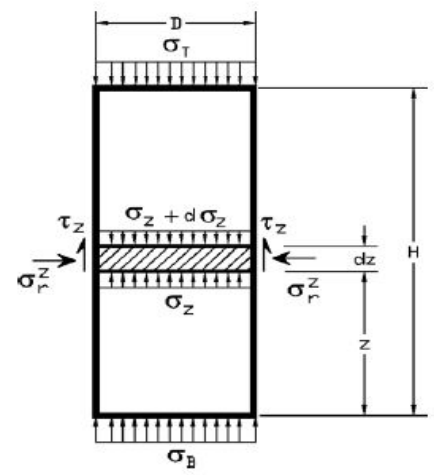

Figure (3) Diagram of stress inside an instrumented die during the powder compaction

Where $\mu$ is the friction coefficient. Using Eqs. (2) and (3) and neglecting the gravitational force, the equilibrium Eq. (1) can be rewritten as:

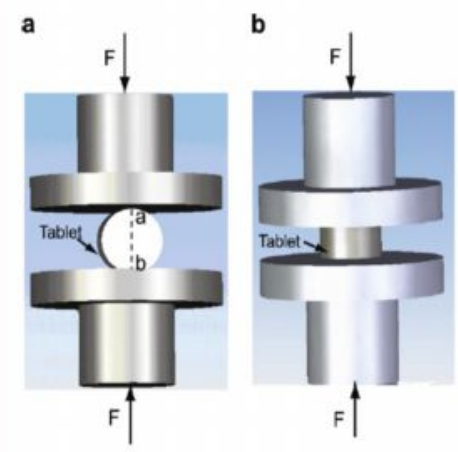

Fig (4) . Tablet strength measurement: (a) radial tensile strength;(b)axial 
$\frac{d \sigma_{z}}{\sigma_{z}}=\frac{4 k \mu}{D} d_{z}$

By assuming the friction coefficient $\mu$ and the stress transmission ratio $K$ are uniformly distributed along the vertical boundary of the powder bed, integration of Eq. (4)gives:

$\ln \frac{\sigma_{z}}{\sigma_{B}}=\frac{4 k \mu}{D} Z \quad(0 \leq z \leq h)$

where $\sigma_{B}$ is the axial stress at the bottom surface of the powder bed. The axial stress at the top surface of the powder bed $\sigma_{T}$ can hence be given as:

$\ln \frac{\sigma_{T}}{\sigma_{B}}=\frac{4 k \mu}{D} h$

From Eqs. (5) and (6), the stress $\sigma_{Z}$ can be expressed in terms of the axial stress at the top and bottom surfaces of the powder bed as following:

$\sigma_{z}=\sigma_{B}\left(\frac{\sigma_{T}}{\sigma_{B}}\right)^{\frac{z}{h}}$

The friction coefficient $\mu$ can be determined from Eq. (6) by using Eqs. (2) and (7):

$\mu=\frac{D}{4 h} \frac{\sigma_{B}}{\sigma_{r}}\left(\frac{\sigma_{T}}{\sigma_{B}}\right)^{\frac{z}{h}} \ln \frac{\sigma_{T}}{\sigma_{B}}$

Eq. (8) is used in this study to determine the friction coefficient $\mu$ from the compaction test with an instrumented die, in which $\sigma_{T}, \sigma_{B}$ and $\sigma_{r}$ are measured with stress sensors.

in order to obtain the intrinsic characteristics of the powder, the influence of die wall friction should be minimized.Two kinds of lubrication methods could be used, magnesium stearate was mixed with powders, while in the external lubrication method the suspension of magnesium stearate was used to lubricate the die wall .It was found that both lubrication methods could reduce the die wall friction coefficient to small value during compaction, It was generally considered that a die wall friction of order 0.1 should have small effect on powder compaction behavior.

After the tablets made by compaction simulators are ejected from the die, their strengths can be measured typically, The radial tensile strength and the axial compressive /tensile strength of tablets are measured, the radial tensile strength of tablets is measured using a diametrical compression test as shown in Fig(4a). Tablets are crushed along their central lines . for maximum crush force, the radial tensile strength of tablets is determined using the following equation [16].

$\sigma_{d}^{f}=\frac{2 F_{\max }}{\pi D t}$

Where $F_{\max }$ is the crushing force, $\mathrm{D}$ is the tablet diameter and the tablet thickness .In order to use Eq .(9) the failure of tablets should be brittle fracture, that is, tablets should be split into two halves along the center line ( see dashed line "ab" in Fig (4a ). The axial compressive strength are measured by uniaxial compression tests as shown in fig. $4 \mathrm{~b}$ the tablet is compressed axially .The axial compression strength is calculated from[16]:

$\sigma_{c}^{f}=\frac{4 F_{y}}{\pi D^{2}}$

Where $F_{y}$ is the axial compression force at the yield point 
Powders are generally assumed to be elastic-plastic materials with appropriate yield surfaces to represent the yield behavior of the materials. There is collection of phenomenological models for yield surfaces of powdered materials, such as the Drucker-Prager Cap(DPC) model,the CamClay model and theDiMaggio-Sandler model .All of these models were originally developed for application in soil mechanics and geotechnique and have been used to simulate the compaction for powder metallurgy and ceramic powders. Among these models, the most widely used yield surface in modeling powder compaction is the Drucker-Prager Cap(DPC) model, not only because it can more reasonably represent both the shear failure and the plastic yielding of granular materials, but also because it can be readily characterised with experiments on real powders [7].A detailed description of the DPC model will be presented .

\section{The Drucker - Prager - Cap}

The Drucker-Prager-Cap model was originally developed to predict the plastic deformation of soils under compression. It consists principally of two intersecting segments: a shear failure segment Fs and a cap segment Fc. A transition segment Ft has been introduced to provide a smooth surface.[15] For the uniaxial compaction, these segments are defined in the p-q plane (see Fig. 5) in terms of two stress invariants: the equivalent pressure stress $\mathrm{p}$ and the Mises equivalent stress $\mathrm{q}$, where[15]

$p=\frac{1}{6}\left(\sigma_{1}+\sigma_{2}+\sigma_{3}\right)$

$q^{2}=\frac{1}{6}\left[\left(\sigma_{1}-\sigma_{2}\right)^{2}+\left(\sigma_{2}-\sigma_{3}\right)^{2}+\left(\sigma_{3}-\sigma_{1}\right)^{2}\right]$

where $\sigma_{i}(\mathrm{i}=1,2,3)$ are the principal stresses. The shear failure segment in the DPC model provides a criterion for the occurrence of shear flow, which is dependent upon the cohesion $\mathrm{d}$ and the angle of friction $\beta$ of the granular materials according to the Mohr-Coulomb hypothesis: [15] $F_{s}(p, t)=t-p \tan \beta-d=0$

The cap segment which intersects the equivalent pressure stress axis is an elliptical curve with constant eccentricity in the $\mathrm{p}-\mathrm{t}$ plane as given by: [15]

$F_{c}(p, t)=\sqrt{\left(p-p_{a}\right)^{2}+\left(\frac{R t}{1+\alpha-\frac{\alpha}{\cos \beta}}\right)^{2}}-\mathrm{R}\left(d+p_{a} \tan \beta\right)=0$

where $\mathrm{R}$ and $\alpha$ are parameters determining the shape of the cap segment and the smooth transition surface between the shear failure segment and the cap segment, respectively. $p_{a}$ is an evolution parameter representing the hardening or softening driven by the volumetric plastic strain, and is given by: [15]

$p_{a}=\frac{p_{b}-R d}{1+R \tan \beta}$

where $p_{b}$ is the hydrostatic pressure yield surface that defined the position of the cap. $p_{b}$ is generally assumed be dependent upon the volumetric inelastic strain $\varepsilon_{v o l}^{i n}$. This dependence controls the hardening or softening of the cap segment; volumetric plastic compaction results in hardening, while volumetric plastic dilation develops softening. the transition segment is always 
relatively small by restricting the parameter $\alpha$ with typical values of 0.01 to 0.05 . The transition segment is given by: [15]

$F_{t}(p, t)=\sqrt{\left(p-p_{a}\right)^{2}+\left[t-\left(1-\frac{\alpha}{\cos \beta}\right)\left(d+p_{a} \tan \beta\right)\right]^{2}}-\alpha\left(d+p_{a} \tan \beta\right)=0 \ldots$

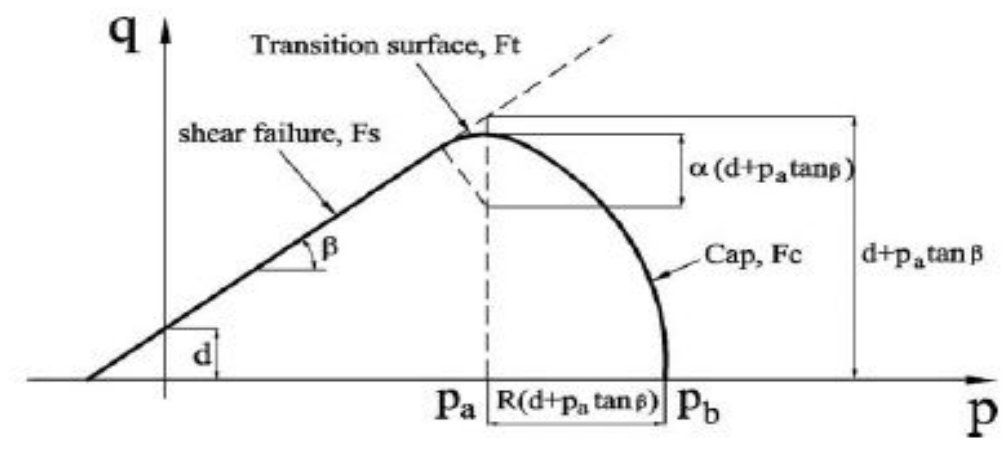

Figure (5) The Drucker - prager model in (p,q) plane. [15]

\section{Density and Stress distribution during compaction}

The relative density distribution at the maximum compression is shown in Fig. 6. It can be seen that the density distribution is not uniform although the initial density was uniform. During compression, a high density zone is developed around the top edge of the powder compact, while a low density zone is located at the bottom rim. The non-uniform density distribution is mainly induced by the friction along the die wall. The presence of friction inhibits the powder moving downwards as the upper punch moves downwards, and consequently the powder around the bottom edge is less compressed

while the powder around the top edge is highly compressed [17]
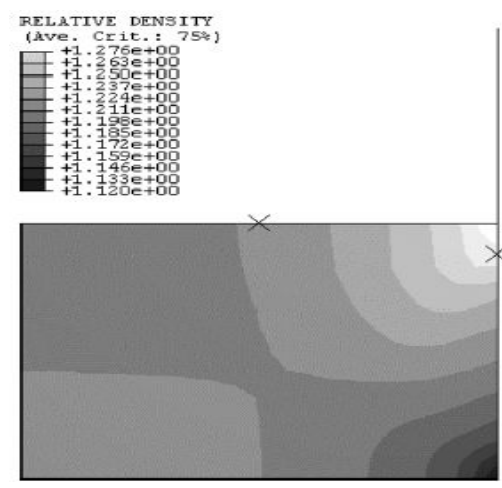

Figure (6) Density distribution at maximum compaction
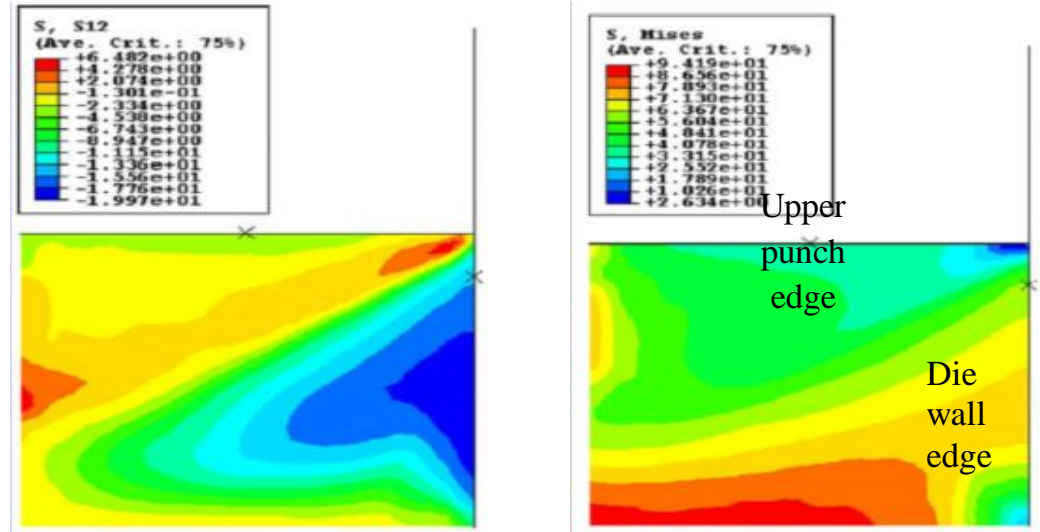

Figure 7. The distribution of (a) von Mises and (b) shear stress during the unloading

During unloading, the retreat of the top punch leads to the relaxation of the compressed powder bed as a result of the recovery of elastic strain. Typical powder behavior during unloading is 
illustrated in Fig. 7, which shows the Von Mises stress and shear stress distributions at instant just after the unloading began. It is clear that the effective stress at the top is generally lower than that at the bottom of the compressed powder bed, (the analysis of Michrafy et al. [18] ). This indicates that the powder near the top will generally relax more than that at the bottom. Close examination of the shear stress distribution (see Fig.7b) reveals that there is an intensive shear band which runs from the top edge towards the mid-centre. Within this shear band the shear stress changes from positive to negative, indicating the change in the direction of the shear stress. Shear deformation in granular materials generally induces dilation of the materials. Consequently, the strength in this zone is relatively low. This is demonstrated by the experimental observation of the failure patterns for the tablets, as shown in Figs. 8 and9.

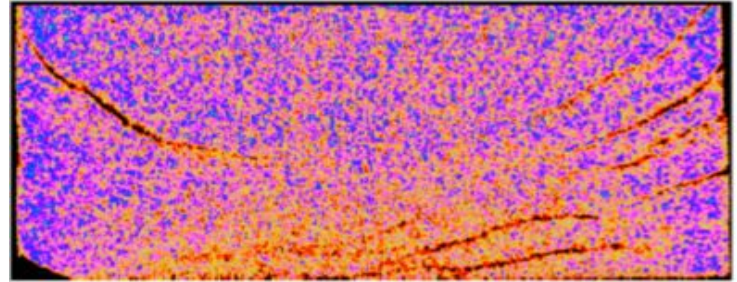

(a)

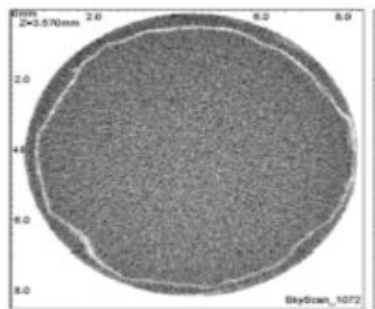

(c)

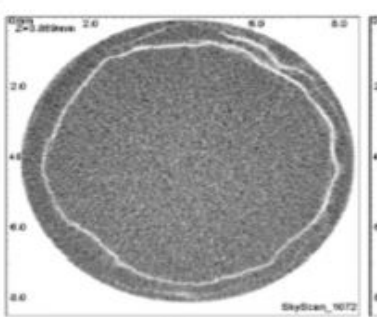

(d)

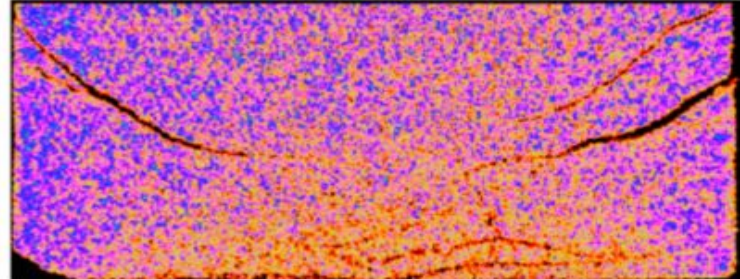

(b)

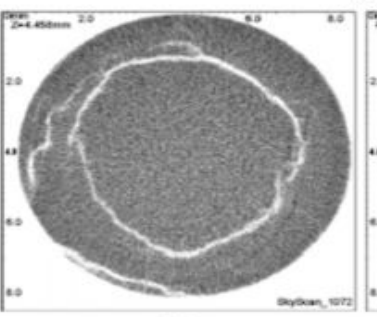

(e)

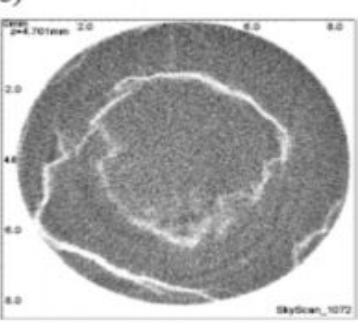

(f)

Figure (8) X-ray images of ejected tablets (a)- (b) vertical slices;(c)-(f) cross section at different height

Fig. 8 shows the X-ray tomographic images of the ejected tablet. It is clear that cracks develop from the top edge towards the bottom centre, similar to the pattern of shear band shown in Fig. 7b. It can also be seen that the main crack is essentially axisymmetric and gradually shrinks towards the bottom centre. This is further illustrated in Fig. 9, which shows the photography of three broken tablets upon ejection in the same series of tests. It is clear that the compacts are broken into two parts: a top cap of an up-side-down cone shape and a base with a concave dip. It has been noticed that the failure patterns shown in Figs. 8 and 9 are a common feature during the tests with this particular powder, even for those tests with the lubricated die. This is not surprising as the same density distribution patterns are produced with different die wall frictions, even though high friction amplifies the density gradients [17]. By comparing the shear stress distribution during unloading shown in Fig. $7 \mathrm{~b}$ with the failure patterns shown in Figs. 8 and 9, it suggests that the diagonal shear band running from

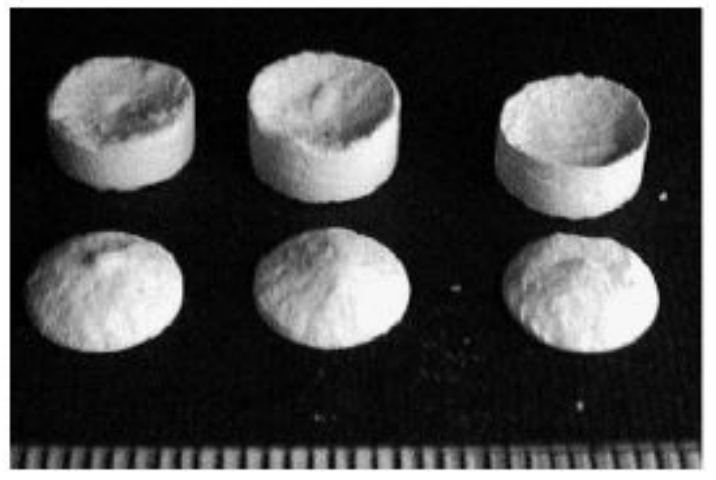

Figure (9) photography of broken tablets upon ejection 
the top edge towards the mid-centre (Fig. 7b) is believed to be responsible for the occurrence of cracks.

\section{Experimental Investigation}

First AISI 410 Stainless Steel is adopted for manufacturing the proposed punches and dies as this material is quit suitable for our attempt by virtue of its principle design features . 410 stainless steel is the basic martensitic stainless which will attain high mechanical properties after heat treatment . It has good impact strength, corrosion and scaling resistance up to $1200 \mathrm{~F}$ (649 C) ,Tough, draggy chips with heavy build - up. While this alloy can be machined in the annealed condition, it tends to perform better in the cold drawn or heat treated condition, its melting point $2790 \mathrm{~F}$, and modulus of Elasticity ( tension) $29 * 10^{6} \mathrm{psi}$, Hardening accomplished by heating to (945-1010 C), followed by oil quenched for maximum hardness, Annealing (649-760 C) followed by air cooling. Also AISI 316L stainless steel(95HRB) was used to manufacture the punch holder.

Hardness tester Model MAT24/CRBV is Brooks Inspection Equipment used to measure the hardness of stainless before and after heat treatment which is found to be 25HRC and 46HRC respectively. Heat treatment is accomplished using the German Furnace type (NABER2804 Lilienthal/Breman,Max temp1200C,15Kw,22.7A,380V)then oil quenched.

Turning Machine Storebro Bruk - Type öRN (2.6-3.7Kw). was used to perform the required design using the sintered carbide insert tool to machine a solid stainless shaft as a raw material used to produce the required design of punches and dies. Several types of grind tools, grind and polished papers are used in the manufacturing procedure , in addition to, drilling and threading, fasteners (slotted countersunk Head Screws) used to join the individual parts of upper and lower punches. Figure(14) presents the schematic diagram of the new manufactured punches and dies with detail and cross section, figures $(10,11,12,13)$ present several photographic pictures of new modified and manufactured punches and dies of sizes $(7,9,10.3,12.53 \mathrm{~mm}$ )., while figure (15) presents the assembled punch and die of $7.9 \mathrm{~mm}$ with press tablet machine, and figure (16) present the front and back view of the pharmaceutical machine. In designing punch and die the class of transition or push fit $(\mathbf{H 7 / k 6 )}$ was adopted .

Table (1) The fit and tolerance of new manufactured punches and dies

\begin{tabular}{|c|c|c|c|c|c|c|c|c|c|}
\hline \multicolumn{9}{|c}{ Hole of Die } & \multicolumn{5}{c|}{ punch } \\
\hline $\begin{array}{c}\text { Basic } \\
\text { size }\end{array}$ & $\begin{array}{c}\text { Upper } \\
\text { tolerance. }\end{array}$ & $\begin{array}{c}\text { Lower } \\
\text { tolerance. }\end{array}$ & $\begin{array}{c}\text { Max. } \\
\text { size }\end{array}$ & $\begin{array}{c}\text { Min } \\
\text { size }\end{array}$ & $\begin{array}{c}\text { Basic } \\
\text { size }\end{array}$ & $\begin{array}{c}\text { Upper } \\
\text { tolerance. }\end{array}$ & $\begin{array}{c}\text { Lower } \\
\text { tolerance. }\end{array}$ & $\begin{array}{c}\text { Max. } \\
\text { size }\end{array}$ & $\begin{array}{c}\text { Min } \\
\text { size }\end{array}$ \\
\hline 7 & +0.015 & 0 & 7.015 & 7 & 7 & +0.010 & +0.001 & 7.01 & 7.001 \\
\hline 7.9 & +0.015 & 0 & 7.915 & 7.9 & 7.9 & +0.010 & +0.001 & 7.91 & 7.901 \\
\hline 9 & +0.015 & 0 & 9.015 & 9 & 9 & +0.010 & +0.001 & 9.01 & 9.001 \\
\hline 10.3 & +0.018 & 0 & 10.318 & 10.3 & 10.3 & +0.012 & +0.001 & 10.312 & 10.301 \\
\hline 12.53 & +0.018 & 0 & 12.548 & 12.53 & 12.53 & +0.012 & +0.001 & 12.542 & 12.531 \\
\hline
\end{tabular}

Table (2) The recommended physical properties of tablets

\begin{tabular}{|c|c|c|}
\hline size & weight & Hardness (SC) of tablet \\
\hline 7 & $100 \mathrm{mg}$ & 4 \\
\hline 7.9 & $200 \mathrm{mg}$ & 7 \\
\hline 9 & $300 \mathrm{mg}$ & 8 \\
\hline 10.3 & $350 \mathrm{mg}$ & $8-12$ \\
\hline
\end{tabular}




\begin{tabular}{|c|c|c|}
\hline 12.53 & $600-700 \mathrm{mg}$ & $10-14$ \\
\hline
\end{tabular}

Tablet-Testing instrument Type PTB311(511)-E is used to test individual, thickness, diameter and hardness of tablets. Which are the most important physical properties that indicate the grantee of test from the physical point of view as follows.
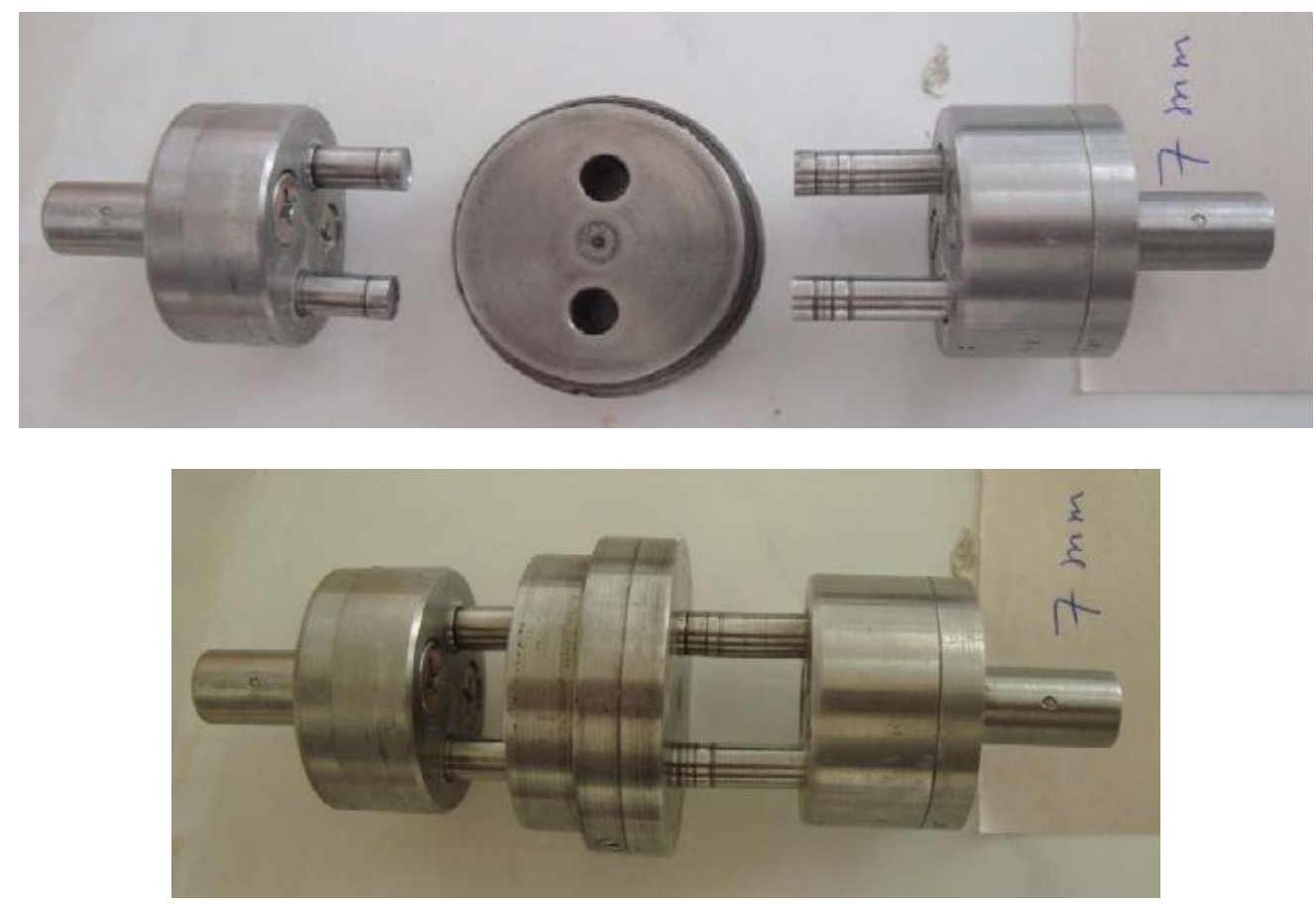

Figure ( 10 ) A new manufactured upper, lower punch and Die of size (7 mm)
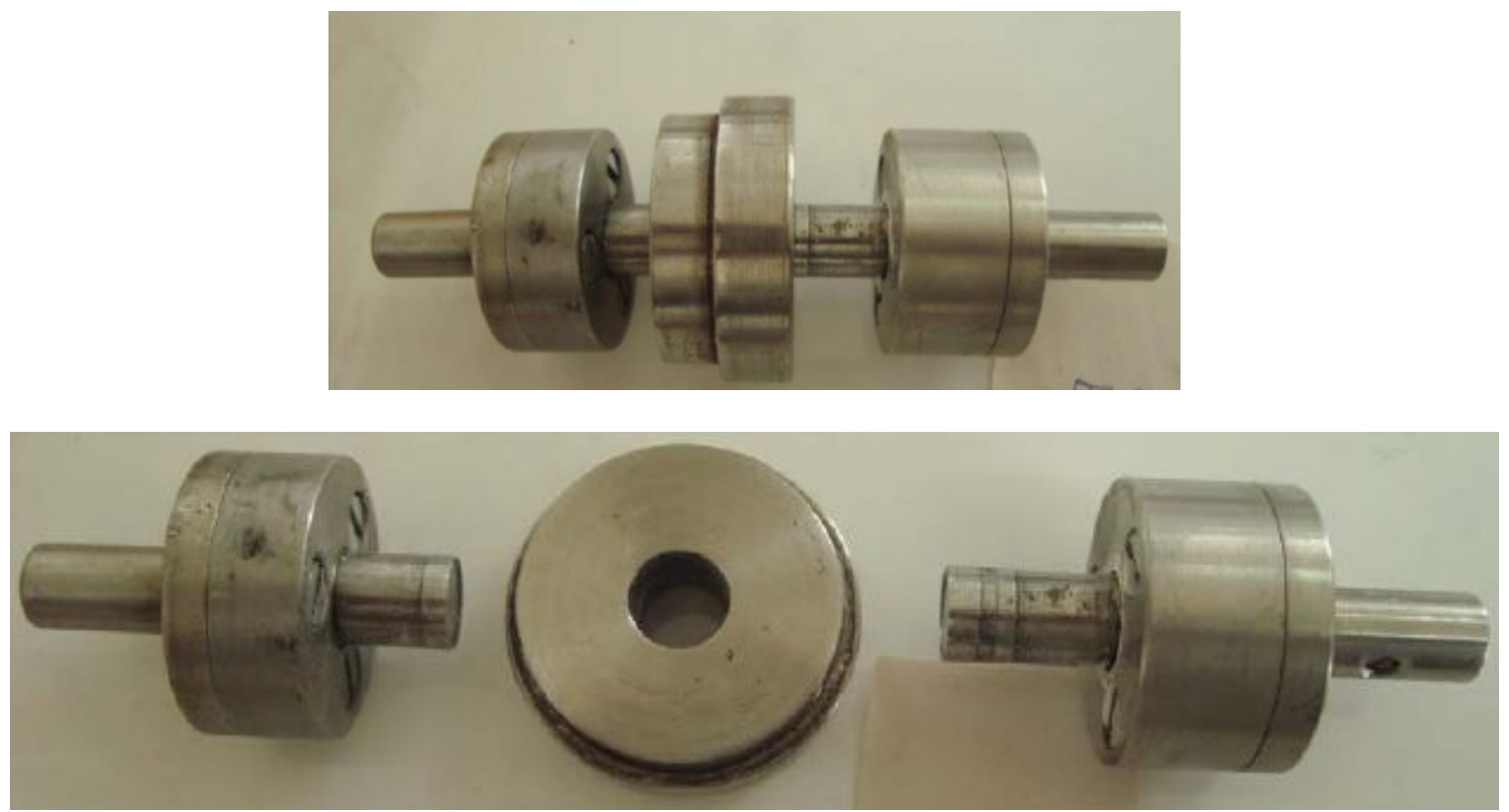
Figure ( 11 ) A new manufactured upper, lower punch and Die of size $(\mathbf{1 2 . 5 3} \mathbf{~ m m})$
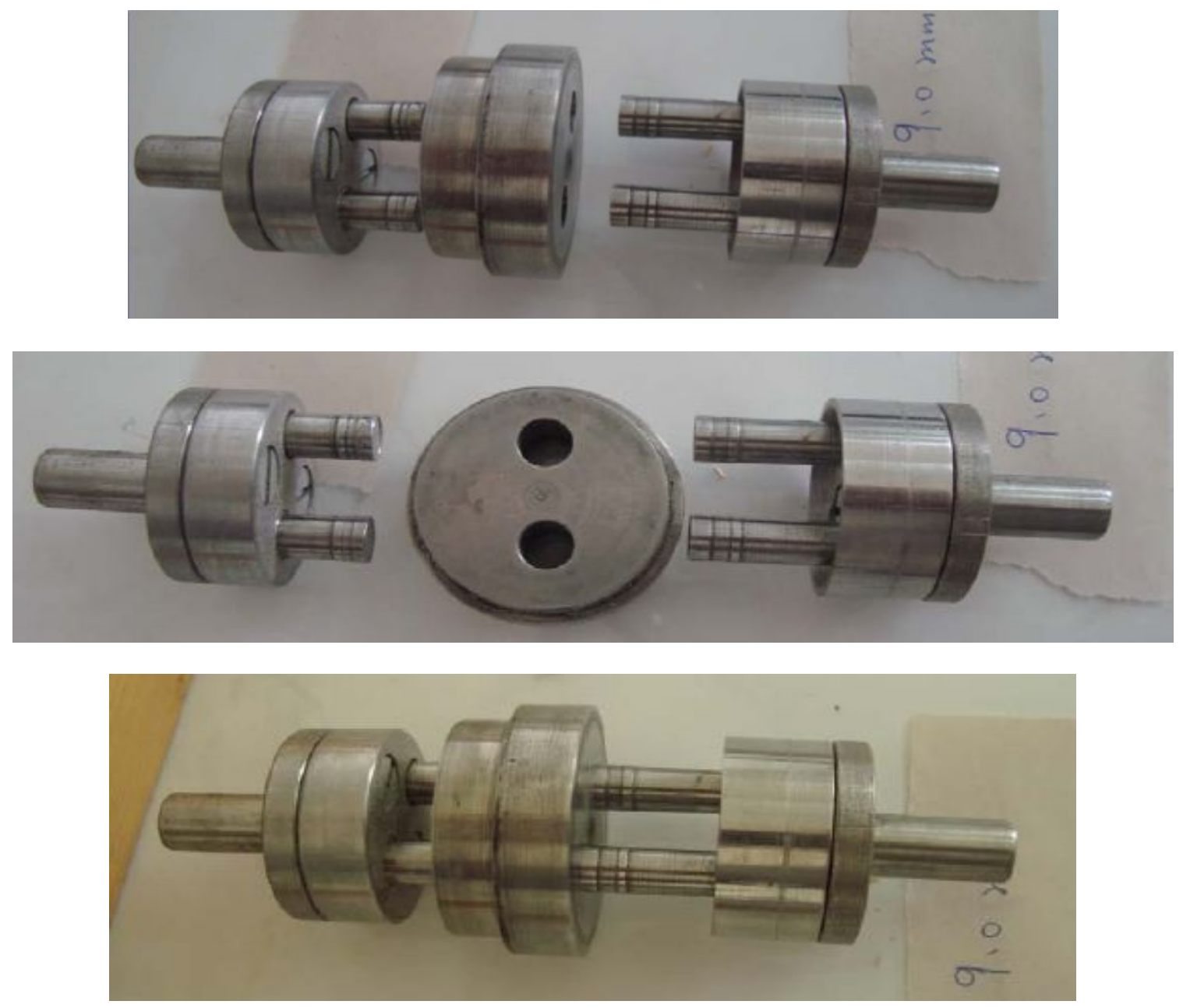

Figure ( 12 ) A new manufactured upper, lower punch and Die of size $(9 \mathrm{~mm})$
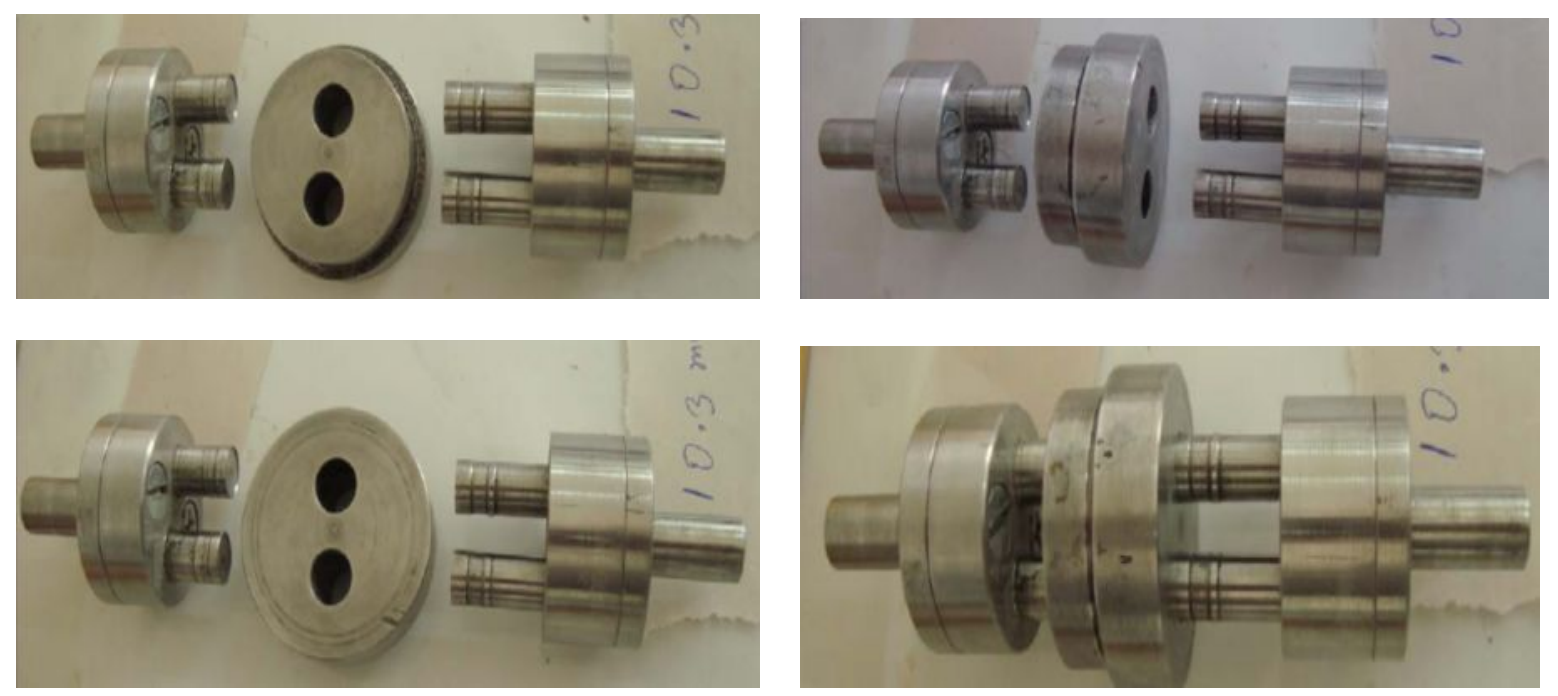
Figure ( 13 ) A new manufactured upper, lower punch and Die of size $(10.3 \mathrm{~mm})$

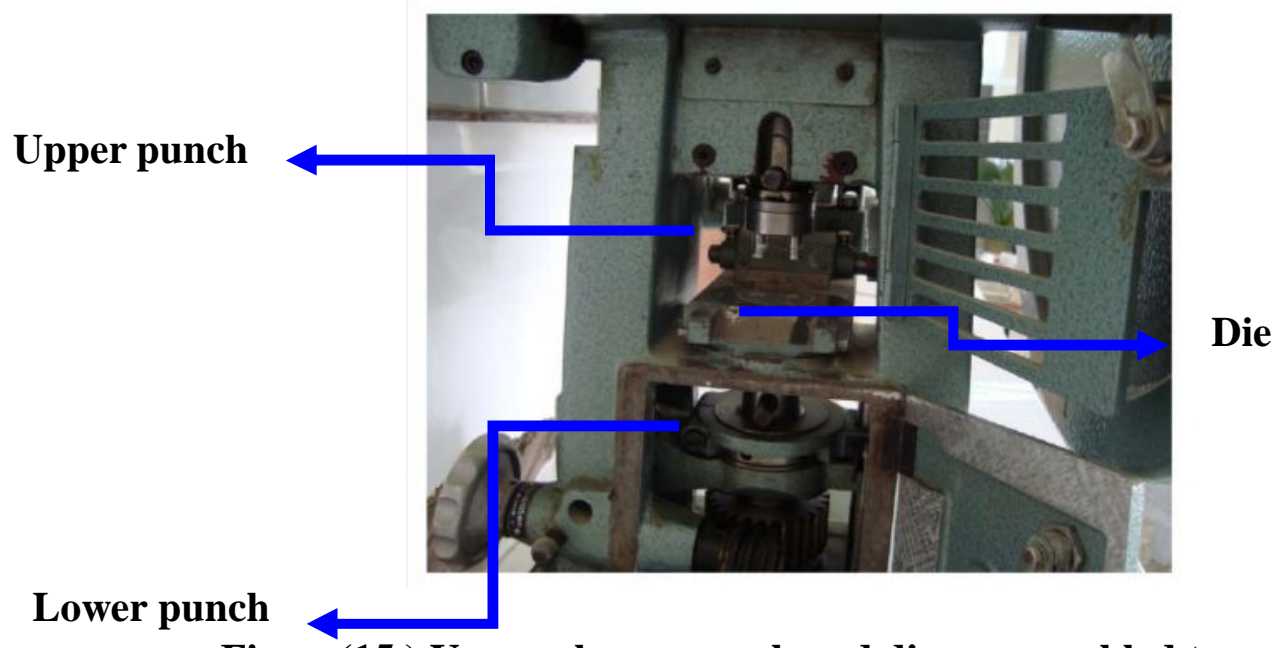

Figure(15 ) Upper, lower punch and die as assembled to machine
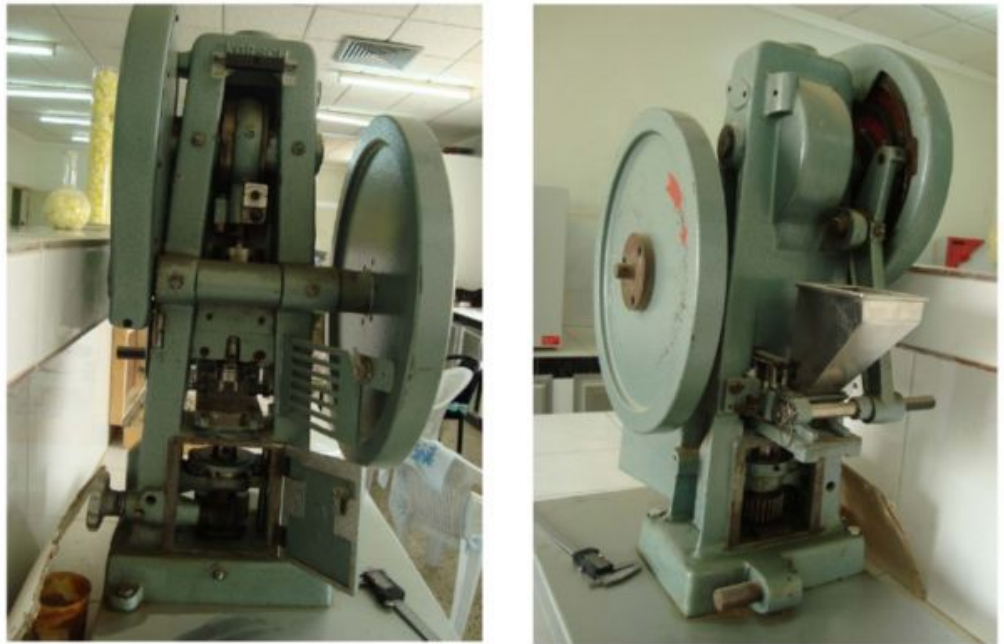

Figure (16) Front and back views of the pharmaceutical tablet press machine

The hardness is performed in compliance to European Pharmacopoeia (EP) and the German Pharmacopoeia (DAB). The force rate can be adjusted to either linear force increase N/ sec or linear speed increase $\mathrm{mm} / \mathrm{min}$ with variable range adjustments. It is recommended to use the linear force increase setting 20/s as this can easily be validated using just a stop watch .Also this setting copies more close the breaking of sample when manually done. [19].

It is important to notice that the desired weight ( desired density ) for specified tablet diameter has a relationship with compression pressure, in other word the compression pressure differs when one wants to produce $100 \mathrm{mg}$ for example from that of $200 \mathrm{mg}$ for the same tablet diameter. here the thickness will change, actually as the weight increases the compression pressure decreases, also as the tablet diameter increase the compression pressure also decreases.

The punches are checked for buckling using the J.B. Johnson formula for analysis regarding the punch as a short column depending on the actual slenderness ratio for column when it is compared to the transition value or column constant $\mathbf{C}_{\mathbf{c}}$, as follows. 
When $\mathrm{KL} / \mathrm{r}<\mathrm{C}_{\mathrm{c}}$, then the column is short, where $C_{c}=\sqrt{\frac{2 \pi^{2} E}{s_{y}}}$

$\mathrm{K}=0.8$ as practical value given for considering the ends of punch as (Fixed- pinned) ends, $\mathbf{S}_{\mathbf{y}}$ : the Yield stress , $\mathbf{E}$ : the modulus of elasticity, $\mathbf{r}$ : radius of gyration, $\quad \mathbf{L}$ : punch length .

J.B. Johnson formula[21]: $P_{c r}=A S_{y}\left[1-\frac{S_{y}(K L / r)^{2}}{4 \pi^{2} E}\right] \quad \ldots 17$

$\mathrm{P}_{\mathrm{cr}}$ : is the critical buckling load, it would have to apply a design factor $[\mathrm{N}]$ to determine the allowable load, Specify N=3.5.

\section{Conclusion}

The existing laboratory machine located in research sector of drug factory operate manually by hand with $7 \mathrm{~mm}$ one punch and die, this study represents an attempt to change existing design of punch and die with another having ability

First to produce two tablet in one run instead of one tablet in one run for size $(7 \mathrm{~mm})$,

Second to produce different sizes of tablet at the factory demand by manufacturing different sets of punches and dies of $(7.9,9,10.3,12.53 \mathrm{~mm})$. with the same space limitation of die and machine itself .

These changes in old design succeeded in producing required factory demands.

\section{References}

[1] C.Y. Wu, L. Dihoru, A.C.F. Cocks, " The flow of powder into simple and stepped dies", Powder Technology 134 (2003) 24- 39.

[2] C.Y. Wu, A.C.F. Cocks, O.T. Gillia, " Die filling and powder transfer", International Journal of Powder Metallurgy 39 (2003) 51- 64.

[3] G. Alderborn, C. Nystrom,“ Pharmaceutical Powder Compaction Technology”, Marcel Dekker Inc., New York, (1996).

[4] R.W. Heckel, "Density-pressure relationship in Powder Compaction",Transactions of the Metallurgical Society of AIME 221 (1961) 671-675.

[5] K.Kawakita, K.H. Ludde, "Some considerations on powder compression equations", Powder Technology 4 (1970/71) 61- 68.

[6] J.T. Carstensen, J.M. Geoffroy, C. Dellamonica,"Compression characteristics of binary mixtures", Powder Technology 62 (1990)

[7] I.C. Sinka, J.C. Cunningham, A. Zavaliangos, "The effect of wall friction in the compaction of pharmaceutical tablets with curved faces: a validation study of the Drucker-Prager cap model", Powder Technology 133 (2003) 33-43.

[8] Burlinson,H.,1968. “Tablets and Tabletting”. Wiliam Heinemann Medical Books Ltd, London.

[9] Aydin,I.,Briscoe, B.J.,Sanliturk, K.Y.,"The internal form of compacted ceramic components:a comparison of a finite element modeling with experiment”. Powder Technology 89, (1996) , 239254.

[10] Coube,O., Riedel, H.,'Numerical simulation of metal powder die compaction with special consideration of cracking". Powder Metallurgy 43 (2),( 2000),123-131.

[11]PM-Modnet-"Modelling-Group,1999.comparison of computer models representing powder compaction process :state of the art review". Powder Metallurgy 42(4),301-311. 
[12] Cunningham, J.C.,Sinka, I.C.,Zavaliangos,A., "Analysis of tablet compaction. I. Characterization of mechanical behavior of powder and powder / tooling friction" . Journal of Pharmaceutical Sciences 93 (8), (2004), 2022-2039.

[13] Frenning ,G., Analysis of pharmaceutical powder compaction using multiplicative hyperelasto- plastic theory. Powder Technology 172 (2), (2007),103-112.

[14] Martin,C.L.,Bouvard ,D.,Shima, S., "Study of particle rearrangement during powder compaction by the discrete element method". Journal of the Mechanics physics of solids 51,(2003),667, 693.

[15]C.Y.Wu ,O.M.Ruddy,A.C.Bentham,B.C.Hancock,S.M.Best,J.A.Elliott."Modelling the mechanical behavior of pharmaceutical powders during compaction". powder Technology 152(2005)107-117.

[16]L.H.Han,J.A.Elliotte,A.C.Bentham,A.Mills,G.E.Amidon,B.C.'Hancock.

Amodified Drucker- Prager Cap model for die compaction simulation of pharmaceutical powders" ,International Journal of Solid and Structures 45(2008)3088-3106.

[17] C.Y. Wu, J.A. Elliott, A.C. Bentham, S.M. Best, B.C. Hancock, W. Bonfield, "A numerical study on the mechanical behaviour of pharmaceutical powders", Proc. Int. Conf. on Pharmaceutics, Biopharmaceutics and Pharmaceutical Technology, 15th-18th March,Nuremberg, Germany, (2004), pp. 17- 18.

[18]A.Michrafy,D.Ringenbacher, P.Techoreloff,"Modeling the compaction behavior of powders: application to pharmaceuticalpowders, "powderTechnology127,(2002),257-266.

[19] Operating manual of tablet - testing instrument type PTB311 (511) - E

[20] R.M. Nedderman, "Statics and Kinematics of Granular Materials",Cambridge

University Press, New York, 1992.

[21] Robert.L.Mott, “ Machine Elements in Mechanical Design “, Fourth Edition,pearson prentice hall,(2004),229-256

[22] Design Data Book. PSG Tech,.Kalaikathir reputed publishers, 1995. 